\title{
Changes in phytochemical content and antioxidant activity during inflorescence development in broccoli
}

\author{
Shiva Ram Bhandari ${ }^{1}$, Jung-Ho Kwak², Jung Su Jo' ${ }^{1}$, and Jun Gu Lee ${ }^{1 *}$ \\ 'Chonbuk National University, College of Agriculture \& Life Sciences, Department of Horticulture, Jeonju 54896, Republic of Korea. \\ "Corresponding author (jungu@jbnu.ac.kr). \\ ${ }^{2}$ Research Policy Bureau, Rural Developmental Administration, Jeonju 54875, Republic of Korea.
}

Received: 4 September 2018; Accepted: 12 November 2018; doi:10.4067/S0718-58392019000100036

\begin{abstract}
This study was performed to monitor glucosinolate (GSL) profile, total phenol, ascorbic acid, total flavonoid contents, and antioxidant activity in florets of six broccoli (Brassica oleracea L. var. italica Plenck) genotypes at three different inflorescence developmental stages. The level of phytochemicals and antioxidant activities varied significantly among genotypes and developmental stages. Out of the eight GSLs identified in this study, only five were present in all genotypes and their respective developmental stages. Glucoraphanin (GRA), a major GSL, was significantly increased towards the later stages of development (1.41 $\mu \mathrm{g} \mathrm{g}^{-1}$ in immature stage of 'Koyoshi' to $10.57 \mu \mathrm{g} \mathrm{g}^{-1}$ in commercial stage of '09FAM295'), whereas glucobrassicin (BRA) showed a reverse accumulation pattern with the highest value at the immature stage (5.10-7.97 $\left.\mu \mathrm{g} \mathrm{g}^{-1}\right)$. Other minor GSLs varied depending on the genotype. Total phenolic and ascorbic acid content increased significantly as maturity progressed in all the genotypes with a relatively higher increment observed in ascorbic acid (65.8\%-100.9\%) than phenolic content (10.2\%-31.2\%). Flavonoid content, on the other hand, showed a cultivardependent accumulation pattern throughout the developmental stages. However, although antioxidant activity increased with inflorescence development, the increment was higher and lower than in total phenol and ascorbic acid content,

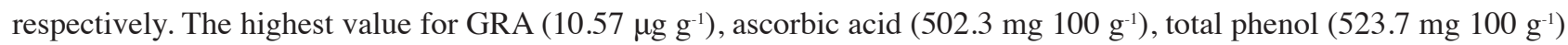
and antioxidant activities was obtained for '09FA-M295' at the commercial stage. Taken together, these results indicate that phytochemicals in broccoli have a differential accumulation pattern during inflorescence development. Regardless of genotypes and inflorescence developmental stage, total phenolic content showed the highest correlation with antioxidant activity $\left(\mathrm{r}=0.779^{* *}\right)$, followed by ascorbic acid $\left(\mathrm{r}=0.674^{* *}\right)$ and flavonoid content $\left(\mathrm{r}=0.602^{* *}\right)$, whereas total GSLs showed a nonsignificant correlation with antioxidant activity.
\end{abstract}

Key words: Antioxidant activities, ascorbic acid, Brassica oleracea var. italica, broccoli floret, developmental stage, glucosinolate, phenolics.

\section{INTRODUCTION}

Broccoli (Brassica oleracea L. var. italica Plenck), which originated from the eastern Mediterranean region of Europe, is one of the most commonly consumed green vegetable worldwide. Broccoli possesses a wide range of bioactive compounds that have several health benefits, and are rich in both nutritional as well as non-nutritional antioxidants such as vitamins $\mathrm{C}$ and E, phenolic compounds, and glucosinolates (GSLs) (Aires et al., 2011; Bhandari and Kwak, 2015; Jo et al., 2016). Several epidemiological studies have shown that consumption of broccoli is positively associated with reduced risk of several types of cancers, type 2 diabetes, and cardiovascular diseases (Razis and Noor, 2013; Bachiega et al., 
2016). Furthermore, broccoli is known to possess antioxidant and anti-proliferative activities (Podsedek, 2007; Bhandari and Kwak, 2015). These beneficial properties can be attributed to the presence of health-promoting phytochemicals such as GSLs, vitamins, carotenoids, phenols, flavonoids, and minerals (Aires et al., 2011; Jo et al., 2016).

Glucosinolates are S-containing and water-soluble compounds that predominantly constitute a major group of phytochemicals present in broccoli. More than 200 GSLs have been reported in different Brassica species (Halkier and Gershenzon, 2006), and the intake of GSLs has been shown to prevent prostate and lung cancer (Bonnesen et al., 2001; Latte et al., 2011). These health benefits are mainly due to the by-products of hydrolysis reactions, such as sulforaphane, iberin, phenethyl alcohol, and allyl-isothiocyanate, which are derived from glucoraphanin, glucoiberin, gluconasturtiin, and sinigrin, respectively, and can prevent cardiovascular disorders and inhibit proliferation of cancer cells (Bonnesen et al., 2001). Further, these intermediates are also known to be responsible for the hot and pungent flavor of the plants (Razis and Noor, 2013). Vitamin C, a water-soluble antioxidant compound, is another health-promoting phytochemical (Munyaka et al., 2010), which contains ascorbic acid and its oxidized product dehydroascorbic acid. Vitamin $\mathrm{C}$ has been shown to protect against cell death, scavenge hydroxyl radicals and hydrogen peroxide, and act as a lipid peroxidation chain-breaking agent (Munyaka et al., 2010). Likewise, phenolic compounds present in broccoli help neutralize or quench free radicals (Cartea et al., 2011) and are often considered to be the most abundant antioxidants in the human diet (Faller and Fialho, 2009). Flavonoids and their derivatives possess antioxidant properties due to their ability to scavenge reactive oxygen species and inhibit oxidative stress (Pourcel et al., 2007). All the antioxidants present in broccoli show stronger interactive antioxidative properties when they work in groups as they function synergistically to reduce reactive oxygen species.

The concentration of these phytochemicals and their properties in broccoli are dependent on both the genotype and environment. Several studies have confirmed significant changes in these phytochemicals based on plant genotype (Jo et al., 2016), growing season (Vallejo et al., 2003; Bhandari and Kwak, 2014), plant parts (Perez-Balibrea et al., 2011; Bhandari and Kwak, 2015), developmental stages (Vallejo et al., 2003), fertilization levels (Fabek et al., 2012), temperature and irrigation (Pek et al., 2012), postharvest storage conditions (Fernandez-Leon et al., 2013), and even the cultivation year (Jo et al., 2018). Furthermore, studies have also been performed to determine the changes in phytochemical contents of broccoli during developmental processes of different plant organs. Head ontogeny may be one such factor that is important in determining the phytochemical contents in broccoli as significant biochemical, physiological, and structural changes occur during this stage (Vallejo et al., 2003; Krumbein et al., 2007). However, studies related to the accumulation patterns of GSLs, functional compounds in broccoli, and antioxidative activities during the developmental processes are limited. Therefore, this study was conducted to determine the influence of the head ontogeny process on GSL concentration, total phenolic and flavonoid content, and antioxidant activities in broccoli florets grown in open field conditions in South Korea.

\section{MATERIALS AND METHODS}

\section{Plant materials and cultivation}

In total, six broccoli genotypes (one commercial cultivar 'Koyoshi' and five new-variety candidates) were used in this study. The seedlings were transplanted to the cultivation field in rows with $50 \mathrm{~cm}$ between plants and $60 \mathrm{~cm}$ between rows, $33 \mathrm{~d}$ after sowing in a randomized block system with 15 broccoli seedlings for each genotype (five seedlings for each developmental stage). All the plants were grown in an open experimental field, and five florets for each developmental stage were harvested at three successive developmental stages: immature, intermediate, and commercial or mature stage, which occurred after 50,57, and $64 \mathrm{~d}$ after transplanting, respectively. The diameter of the florets was 1-3, 5-10, and 14-17 $\mathrm{cm}$ during the immature (I), intermediate (II) and commercial (III) stages, respectively (data not shown). Water, fertilizers, and pesticides were applied according to standard cultural practices of the National Institute of Horticultural and Herbal Science, Rural Development Administration, Republic of Korea. Five florets for each developmental stage were collected. After harvest, florets were cut into small pieces, and freeze-dried. The samples were ground into a fine powder and stored at $-20{ }^{\circ} \mathrm{C}$ until they were analyzed for phytochemicals and antioxidant activities.

\section{Analysis of GSLs}

Sample preparation and GSLs analyses were performed according to methods described by Bhandari and Kwak (2015). First, freeze-dried powder samples $(0.1 \mathrm{~g})$ were extracted with $1 \mathrm{~mL}$ boiling methanol (70\%) for $20 \mathrm{~min}$ and centrifuged 
at $8900 \times \mathrm{g}$ for $10 \mathrm{~min}$ at $4{ }^{\circ} \mathrm{C}$, after which the pellet was re-extracted and supernatants were combined. The crude GSL extract was then loaded onto a Mini Bio-Spin Chromatography Column (Bio-Rad Laboratories, Hercules, California, USA) containing $0.5 \mathrm{~mL}$ diethylaminoethyl (DEAE)-Sephadex A-25 (Sigma-Aldrich, St. Louis, Missouri, USA), which was pre-activated with $0.1 \mathrm{M}$ sodium acetate (pH 4.0). Next, $200 \mu \mathrm{L}$ purified aryl sulfatase (EC 3.1.6.1, type H-1 from Helix pomatia; Sigma-Aldrich) was added for desulfation, the column was capped, and left for $24 \mathrm{~h}$ at room temperature. The desulfo-GSLs were then eluted with $1.5 \mathrm{~mL}$ distilled water, filtered through a $0.2-\mu \mathrm{m}$ syringe filter and injected into ultra-performance liquid chromatography (UPLC) (H-Class, Waters Co., Milford, Massachusetts, USA) using an Acquity UPLC BEH-C18 column $(1.7 \mu \mathrm{m}, 2.1 \times 100 \mathrm{~mm}$; Waters Co.), and measured at $229 \mathrm{~nm}$ with a photodiode array (PDA) detector. Solvent A ( $100 \%$ distilled water) and solvent B (20\% acetonitrile) were used for eluting compounds at a flow rate of $0.2 \mathrm{~mL} \mathrm{~min}^{-1}$. The gradient programs were as follows: a linear step from $1 \%$ to $99 \%$ of solvent B within 6 min, followed by constant conditions for up to $10 \mathrm{~min}$ and then a quick drop down to $1 \%$ of solvent $\mathrm{B}$ at $12 \mathrm{~min}$ and isocratic conditions with $1 \%$ of solvent B up to $15 \mathrm{~min}$. Authentic standards of $10 \mathrm{GSLs}$, namely, glucoiberin (IBE), progoitrin (PRO), epiprogoitrin (EPI), glucoraphanin (GRA), sinigrin (SIN), gluconapin (NAP), glucobrassicanapin (BCN), glucoerucin (ERU), glucobrassicin (BRA), and gluconasturtiin (NAS) (Cfm Oskar Tropitzsch GmbH, Marktredwitz, Germany) were desulfated and used to identify the peaks and their areas were used to quantify GSLs, expressed as $\mu \mathrm{mol} \mathrm{g}^{-1}$ dry weight.

\section{Analysis of total phenol}

The total phenolic content was estimated using the Folin-Ciocalteu colorimetric method based on the procedure of Bhandari and Lee (2016) using gallic acid as a standard. Briefly, freeze-dried and powdered broccoli samples $(0.1 \mathrm{~g})$ were mixed in $1.5 \mathrm{~mL} 80 \%$ methanol and extracted in an orbital shaker set at $50{ }^{\circ} \mathrm{C}$ for $1 \mathrm{~h}$ in a water bath. Next, the extract was centrifuged at $4000 \times \mathrm{g}$ for $10 \mathrm{~min}$ at $4{ }^{\circ} \mathrm{C}$ and filtered through $0.45-\mu \mathrm{m}$ syringe filters, and $200 \mu \mathrm{L}$ supernatant was mixed with $0.6 \mathrm{~mL}$ distilled water in a $1.5-\mathrm{mL}$ tube. After adding $200 \mu \mathrm{L}$ Folin reagent (Sigma-Aldrich), the solution was incubated in a water bath at $27^{\circ} \mathrm{C}$ for $5 \mathrm{~min}$. Subsequently, $0.2 \mathrm{~mL} 7 \%$ sodium carbonate (Sigma-Aldrich) solution was added, and the absorbance of the extract was measured using a microplate spectrophotometer (Multiskan TM GO, Thermo Scientific Inc., Waltham, Massachusetts, USA) after $1 \mathrm{~h}$. Gallic acid (Sigma-Aldrich) was used as a standard at different concentrations (5.0-100.0 $\mu \mathrm{g} \mathrm{mL}^{-1}$ ) for calibration. Total phenolic compounds were expressed as mg gallic acid equivalent per $100 \mathrm{~g}$ dry weight.

\section{Analysis of ascorbic acid content}

The ascorbic acid content was analyzed according to the methods described by Bhandari and Kwak (2015). Briefly, freezedried and powdered broccoli samples $(0.5 \mathrm{~g})$ were extracted with $5 \%$ metaphosphoric acid solution. After centrifugation at $4000 \times \mathrm{g}$ for $5 \mathrm{~min}$ and filtration (with a $0.20 \mu \mathrm{m}$ syringe filter), the aliquot was analyzed using an UPLC (Waters) system equipped with an Acquity UPLC HSS T3 $(2.1 \times 100 \mathrm{~mm}, 1.8 \mu \mathrm{m}$, Waters) column and PDA detector (Waters) at $254 \mathrm{~nm}$. The mobile phase was composed of an isocratic aqueous solution of $0.1 \%(\mathrm{v} / \mathrm{v})$ formic acid at a flow rate of 0.3 $\mathrm{mL} \mathrm{min}^{-1}$. An authentic L-ascorbic acid standard (Sigma-Aldrich) at various concentrations $(5,10,25,50$, and $100 \mu \mathrm{g} \mathrm{mL}$ 1) was used to identify and quantify the peak, and ascorbic acid content was expressed as mg $100 \mathrm{~g}^{-1}$ dry weight.

\section{Analysis of flavonoids}

Flavonoid analyses were performed according to Bhandari and Lee (2016) with some modifications. Briefly, lyophilized broccoli samples $(1.0 \mathrm{~g})$ were hydrolyzed and extracted in $10 \mathrm{~mL} 50 \% \mathrm{MeOH}$ containing $1.2 \mathrm{M} \mathrm{HCl}$ and $0.4 \mathrm{~g} \mathrm{~L}^{-1}$ tertbutylhydroquinone (TBHQ) for $2 \mathrm{~h}$ at $80^{\circ} \mathrm{C}$. Next, the samples were cooled to $25^{\circ} \mathrm{C}$, centrifuged at $2400 \times \mathrm{g}$ for $10 \mathrm{~min}$, and diluted with $\mathrm{MeOH}$. The aliquot was filtered through a $0.2-\mu \mathrm{m}$ syringe filter, and $10 \mu \mathrm{L}$ aliquot was analyzed using a Breeze 2 HPLC system (Waters Co.) equipped with a Waters 1525 binary HPLC pump, Waters 717 plus auto-sampler and Waters 2489 UV/Visible detector. Separation was performed in XBridge C18 $5 \mu \mathrm{m}(4.6 \times 150 \mathrm{~mm})$ column at $210 \mathrm{~nm}$. The mobile phase consisted of $10 \%$ methanol (A) and $100 \%$ methanol (B), both adjusted to $\mathrm{pH} 2.5$ with trifluoro-acetic acid. The linear gradient used at a flow rate of $0.6 \mathrm{~mL} \mathrm{~min}{ }^{-1}$ was as follows: $100-65 \% \mathrm{~A}, 0 \%-35 \% \mathrm{~B}(0-20 \mathrm{~min})$, held up to $28 \mathrm{~min}$ at same condition, $65 \%-50 \% \mathrm{~A}, 35 \%-50 \% \mathrm{~B}$ (28-40 min), held up to $45 \mathrm{~min}$ at same condition, $50 \%-0 \%$ A, 50\%-100\% B (46-50 min), held up to $55 \mathrm{~min}$ at same condition, and 0\%-100\% A, 100\%-0\% B (55-65 min). All the chemicals and standards (kaempferol, quercetin, luteolin, myricetin, and apigenin) were obtained from Sigma-Aldrich. 
Identification and quantification of individual flavonoid were carried out using commercial standards with the linear range of $0.5-10.0 \mu \mathrm{g} \mathrm{mL}{ }^{-1}$. All samples analyses were carried out in triplicates, and the results were expressed as $\mathrm{mg}$ per $100 \mathrm{~g}$ dry weight (mg $\left.100 \mathrm{~g}^{-1} \mathrm{DW}\right)$.

\section{Determination of antioxidant activities}

Similar extraction protocol applied for the total phenol content analysis was used to measure antioxidant activities. The antioxidant activities in broccoli samples were evaluated using three different methods. Free radical scavenging activity was measured using the 2,2,-diphenyl-1-picrylhydrazyl (DPPH) assay according to Bhandari and Kwak (2015). For this, $100 \mu \mathrm{L}$ DPPH solution was added to $100 \mu \mathrm{L}$ sample extract at different concentrations $\left(0.5,1.0,1.5,2.5\right.$, and $\left.5.0 \mathrm{mg} \mathrm{mL}^{-1}\right)$ in 96-well plates. The absorbance of the resultant solution was measured using an EON microplate spectrophotometer (BioTek Instruments Inc., Winooski, Vermont, USA) at $517 \mathrm{~nm}$ after $30 \mathrm{~min}$ of incubation in darkness using $80 \% \mathrm{MeOH}$ without DPPH as a blank. Likewise, the absorbance of samples was measured after mixing $100 \mu \mathrm{L}$ samples with $100 \mu \mathrm{L}$ $80 \%$ methanol. Next, $\mathrm{IC}_{50}$ value, the concentration required to obtain $50 \%$ antioxidant capacity, was calculated and used to compare the radical scavenging activity of sample extracts.

Ferric-reducing antioxidant power (FRAP) assay was performed according to Bhandari and Lee (2016). First, the following stock solutions were prepared: $300 \mathrm{mM}$ acetate buffer $\left(3.1 \mathrm{~g} \mathrm{C}_{2} \mathrm{H}_{3} \mathrm{NaO}_{2} \cdot 3 \mathrm{H}_{2} \mathrm{O}, 16 \mathrm{~mL} \mathrm{C}_{2} \mathrm{H}_{4} \mathrm{O}_{2}\right), \mathrm{pH} 3.6 ; 10 \mathrm{mM}$ 2,4,6-tripyridyl-s-triazine (TPTZ) solution in $40 \mathrm{mM} \mathrm{HCl}$, and $20 \mathrm{mM} \mathrm{FeCl}{ }_{3} \cdot 6 \mathrm{H}_{2} \mathrm{O}$ solution, and a fresh working solution was prepared by mixing acetate buffer, TPTZ solution, and $\mathrm{FeCl}_{3} \cdot 6 \mathrm{H}_{2} \mathrm{O}$ solution in 10:1:1 ratio (v/v/v). The broccoli aliquot $(50 \mu \mathrm{L})$ was then allowed to react with $950 \mu \mathrm{L}$ FRAP solution for $10 \mathrm{~min}$ at $37^{\circ} \mathrm{C}$, and the absorbance of colored product (ferrous tripyridyltriazine complex) was then taken at $593 \mathrm{~nm}$ using a micro plate spectrophotometer (Multiskan GO; Thermo Scientific). A linear standard curve was made between 25 and $800 \mu$ mol 6-hydroxy-2,5,7,8-tetramethylchroman2-carboxylic acid (Trolox) and the results were expressed in mmol Trolox equivalents (TE) $100 \mathrm{~g}^{-1} \mathrm{DW}$.

A 2,2'-azino-bis(3-ethylbenzothiazoline-6-sulfonic acid) (ABTS) assay was measured according to the method described by Thaipong et al. (2006) with some modifications. The ABTS radical cation (ABTS $)$ was prepared by reacting $7.4 \mathrm{mM} \mathrm{ABTS}^{+}$and $2.6 \mathrm{mM}$ potassium persulfate solution for $12 \mathrm{~h}$ at room temperature in the dark. The solution was then diluted with methanol to an absorbance of approximately $0.90 \pm 0.02$ at $734 \mathrm{~nm}$. The extract $(50 \mu \mathrm{L})$ was then allowed to react with $950 \mu \mathrm{L} \mathrm{ABTS}^{+}$solution for $2 \mathrm{~h}$ in the dark, and absorbance was measured at $734 \mathrm{~nm}$ using a microplate spectrophotometer. Trolox at different concentrations (100-1000 $\mu \mathrm{mol})$ was used to obtain a standard curve, and the results are expressed in $\mathrm{mM}$ Trolox equivalents (TE) $100 \mathrm{~g}^{-1} \mathrm{DW}$. The chemicals and standards used for the analyses were purchased from Sigma-Aldrich.

\section{Statistical analyses}

For each sample, three independent replicate measurements were used in all statistical analyses. To determine differences among crop types, cultivars, and plant parts, one way ANOVA followed by Duncan's multiple range test (DMRT) was performed at a significance level of 0.05 using SPSS version 20 (IBM, Armonk, New York, USA).

\section{RESULTS AND DISCUSSION}

\section{Variation in GSL profile}

Total and individual GSL concentrations varied significantly with genotype and developmental stages (Table 1). Altogether, eight GSLs were identified in this study, out of which five GSLs (glucoraphanin: GRA, glucobrassicanapin: BCN, glucoerucin: ERU, glucobrassicin: BRA and gluconastrutiin: NAS) were present in all the genotypes and throughout the developmental stages. In the immature stage, both GRA and BRA were the most abundant depending on the genotype, whereas GRA was the most abundant in the commercial florets, followed by BRA and other GSLs. Similar trends have been previously reported by Wang et al. (2012) and Bhandari and Kwak (2014) in various broccoli cultivars; however, the levels obtained in this study were relatively high, which might be due to the difference in genotypes and growth conditions (Fabek et al., 2012; Jo et al., 2016). GRA differed significantly among the genotypes as well as developmental stages ranging from $1.41 \mu \mathrm{g} \mathrm{g}^{-1}$ (in immature stage of Koyoshi) to $10.57 \mu \mathrm{g} \mathrm{g}^{-1}$ (in commercial stage of 09FA-M295). However, the variation among the genotypes was higher than at the respective maturity stages. This is because GRA content in 
Table 1. Glucosinolate (GSL) profile and concentrations in the heads of various broccoli cultivars at different stages of maturation.

\begin{tabular}{|c|c|c|c|c|c|c|c|c|c|c|}
\hline Genotype & $\begin{array}{l}\text { Maturation } \\
\text { stage }\end{array}$ & IBE & PRO & GRA & NAP & $\mathrm{BCN}$ & ERU & BRA & NAS & Total GSL \\
\hline & & & & & & $\mu \mathrm{mol} \mathrm{g} \mathrm{g}^{-1} \mathrm{D}$ & & & & \\
\hline \multirow[t]{3}{*}{ 09FA-M295 } & I & ND & ND & $7.82 \pm 0.01 \mathrm{~b}$ & ND & $0.06 \pm 0.00 \mathrm{a}$ & $0.09 \pm 0.00 \mathrm{a}$ & $7.04 \pm 0.06 \mathrm{c}$ & $0.20 \pm 0.00 \mathrm{a}$ & $15.22 \pm 0.05 \mathrm{c}$ \\
\hline & II & ND & ND & $6.67 \pm 0.44 a$ & ND & $0.14 \pm 0.00 \mathrm{~b}$ & $0.19 \pm 0.00 \mathrm{~b}$ & $3.41 \pm 0.08 b$ & $0.35 \pm 0.01 b$ & $10.77 \pm 0.54 a$ \\
\hline & III & ND & ND & $10.57 \pm 0.50 \mathrm{c}$ & ND & $0.15 \pm 0.01 b$ & $0.37 \pm 0.01 \mathrm{c}$ & $2.32 \pm 0.03 \mathrm{a}$ & $0.39 \pm 0.02 \mathrm{c}$ & $13.80 \pm 0.48 \mathrm{~b}$ \\
\hline \multirow[t]{3}{*}{ 10FA-M806 } & I & ND & ND & $4.53 \pm 0.34 \mathrm{a}$ & ND & $0.06 \pm 0.01 \mathrm{a}$ & $0.29 \pm 0.02 b$ & $7.21 \pm 0.21 \mathrm{c}$ & $0.26 \pm 0.02 \mathrm{a}$ & $12.35 \pm 0.58 b$ \\
\hline & II & ND & ND & $5.13 \pm 0.12 b$ & ND & $0.15 \pm 0.01 b$ & $0.24 \pm 0.01 \mathrm{a}$ & $4.75 \pm 0.12 b$ & $0.36 \pm 0.01 \mathrm{c}$ & $10.63 \pm 0.11 a$ \\
\hline & III & ND & ND & $6.52 \pm 0.19 c$ & ND & $0.15 \pm 0.01 b$ & $0.23 \pm 0.01 \mathrm{a}$ & $3.59 \pm 0.04 \mathrm{a}$ & $0.32 \pm 0.01 b$ & $10.81 \pm 0.21 \mathrm{a}$ \\
\hline \multirow[t]{3}{*}{ 10FA-M853 } & I & ND & ND & $5.51 \pm 0.62 \mathrm{a}$ & ND & $0.10 \pm 0.00 \mathrm{a}$ & $0.29 \pm 0.01 b$ & $7.43 \pm 0.14 c$ & $0.30 \pm 0.00 \mathrm{a}$ & $13.63 \pm 0.76 a$ \\
\hline & II & ND & ND & $7.52 \pm 0.22 b$ & ND & $0.15 \pm 0.00 \mathrm{~b}$ & $0.23 \pm 0.00 \mathrm{a}$ & $4.45 \pm 0.17 b$ & $0.35 \pm 0.01 b$ & $12.69 \pm 0.16 a$ \\
\hline & III & ND & ND & $8.81 \pm 0.25 c$ & ND & $0.19 \pm 0.01 \mathrm{c}$ & $0.38 \pm 0.01 \mathrm{c}$ & $3.26 \pm 0.11 \mathrm{a}$ & $0.31 \pm 0.01 \mathrm{a}$ & $12.94 \pm 0.27 \mathrm{a}$ \\
\hline \multirow[t]{3}{*}{ 12FA-M296 } & I & $1.84 \pm 0.07 b$ & ND & $4.05 \pm 0.06 \mathrm{a}$ & ND & $0.08 \pm 0.00 \mathrm{a}$ & $0.19 \pm 0.00 \mathrm{c}$ & $7.61 \pm 0.10 \mathrm{c}$ & $0.55 \pm 0.02 c$ & $14.32 \pm 0.17 b$ \\
\hline & II & $1.77 \pm 0.04 b$ & ND & $5.79 \pm 0.20 b$ & ND & $0.12 \pm 0.00 \mathrm{c}$ & $0.09 \pm 0.00 \mathrm{a}$ & $3.55 \pm 0.09 b$ & $0.04 \pm 0.00 \mathrm{a}$ & $11.36 \pm 0.33 a$ \\
\hline & III & $1.15 \pm 0.05 \mathrm{a}$ & ND & $6.94 \pm 0.23 c$ & ND & $0.10 \pm 0.00 \mathrm{~b}$ & $0.11 \pm 0.00 \mathrm{~b}$ & $3.04 \pm 0.05 \mathrm{a}$ & $0.45 \pm 0.01 b$ & $11.79 \pm 0.17 \mathrm{a}$ \\
\hline \multirow[t]{3}{*}{ 12FA-M413 } & I & ND & ND & $5.26 \pm 0.14 \mathrm{a}$ & ND & $0.11 \pm 0.00 \mathrm{a}$ & $0.33 \pm 0.01 b$ & $5.10 \pm 0.01 b$ & $0.23 \pm 0.01 b$ & $11.03 \pm 0.14 b$ \\
\hline & II & ND & ND & $5.68 \pm 0.25 a$ & ND & $0.14 \pm 0.00 \mathrm{~b}$ & $0.21 \pm 0.01 \mathrm{a}$ & $3.07 \pm 0.11 \mathrm{a}$ & $0.24 \pm 0.01 \mathrm{~b}$ & $9.33 \pm 0.14 \mathrm{a}$ \\
\hline & III & ND & ND & $7.78 \pm 0.35 b$ & ND & $0.17 \pm 0.00 \mathrm{c}$ & $0.20 \pm 0.00 \mathrm{a}$ & $3.20 \pm 0.12 \mathrm{a}$ & $0.18 \pm 0.00 \mathrm{a}$ & $11.53 \pm 0.46 b$ \\
\hline \multirow[t]{3}{*}{ Koyoshi } & I & ND & $0.36 \pm 0.01 \mathrm{a}$ & $1.41 \pm 0.02 \mathrm{a}$ & $0.22 \pm 0.01 \mathrm{a}$ & $0.10 \pm 0.00 \mathrm{a}$ & $0.26 \pm 0.00 \mathrm{~b}$ & $7.97 \pm 0.07 b$ & $0.18 \pm 0.00 \mathrm{a}$ & $10.49 \pm 0.05 b$ \\
\hline & II & ND & $0.99 \pm 0.02 b$ & $2.08 \pm 0.17 b$ & $0.49 \pm 0.02 b$ & $0.12 \pm 0.01 b$ & $0.14 \pm 0.00 \mathrm{a}$ & $5.32 \pm 0.17 \mathrm{a}$ & $0.30 \pm 0.01 \mathrm{c}$ & $9.43 \pm 0.35 a$ \\
\hline & III & ND & $1.44 \pm 0.03 c$ & $2.50 \pm 0.07 \mathrm{c}$ & $0.52 \pm 0.01 \mathrm{c}$ & $0.14 \pm 0.01 \mathrm{c}$ & $0.13 \pm 0.00 \mathrm{a}$ & $5.51 \pm 0.29 a$ & $0.24 \pm 0.01 b$ & $10.48 \pm 0.36 b$ \\
\hline
\end{tabular}

Values are mean $\pm \mathrm{SD}$ of three replicates.

Different letters within the column of each genotype are significant based on Duncan's multiple-range test at $\mathrm{p}<0.05$.

IBE: Glucoiberin; PRO: progoitrin; GRA: glucoraphanin; NAP: gluconapin; BCN: glucobrassicanapin; ERU: glucoerucin; BRA:

glucobrassicin; NAS: gluconasturtiin; I: immature, II: intermediate; III: commercial or mature; ND: not detected.

broccoli is highly dependent on the genotype of the plant (Perez-Balibrea et al., 2011). All the new-variety candidates showed significantly higher GRA than the commercial cultivar. This suggests a higher pharmacological value of these new varieties than that of the commercial cultivar. GRA after degradation changes into sulforaphane, which in turn has the ability to induce the activity of phase II detoxification enzymes and inhibit carcinogenesis and tumor growth by inducing apoptosis and cell cycle arrest in cancer cell lines (Traka and Mithen, 2009; Li et al., 2013). Further, we show that GRA content increased as the maturity progressed in all the cultivars, however these results are inconsistent with the previous reports by Vallejo et al. (2003), who reported continuous decrement in GRA during the maturity process. BRA showed decreasing accumulation as the maturity progressed in most of the genotypes with the highest value in the initial immature stages which was inconsistent to the report by Vallejo et al. (2003). Furthermore, BRA content found in this study was quite higher than that observed by Bhandari and Kwak (2014) and lower than that observed by Vallejo et al. (2003). The other GSLs, BCN, ERU, and NAS, showed genotype-dependent dominance in different maturity stages, whereas progoitrin (PRO) and gluconapin (NAP), which were only found in the commercial cultivar, showed similar trend as in GRA, while IBE, found only in 12FA-M296, showed decreasing accumulation as in the BRA.

Total GSL concentration varied from 9.43 to $15.22 \mu \mathrm{g} \mathrm{g}^{-1}$ regardless of developmental stage and genotypes of broccoli. The values observed were within the range found by Wang et al. (2012), who found 1.85-36.68 $\mu \mathrm{g} \mathrm{g}^{-1}$ of total GSLs in 148 broccoli genotypes. However, the value found in this study was higher than that found by Bhandari and Kwak (2014). In contrast to the GRA, total GSL concentration was the highest in the immature stage in most of the cultivars because of the higher contribution of BRA in the immature stage.

\section{Variation in flavonoid content}

Four flavonoids were detected in all the cultivars (Table 2). Kaempferol was the most dominant flavonoid followed by apigenin, quercetin, and myricetin in all the cultivars and their respective developmental stages. Almost all the cultivars possessed significantly higher individual flavonoid content either in the intermediate or the commercial stage than in the immature stage. The content of kaempferol, apigenin, quercetin, and myricetin ranged from 0.68 to $5.72,0.31$ to 2.39 , 0.14 to 0.82 , and 0.00 to $0.66 \mathrm{mg} 100 \mathrm{~g} \mathrm{~g}^{-1} \mathrm{DW}$, respectively. The levels of kaempferol and quercetin in this study were 
Table 2. Flavonoid content in the heads of various broccoli cultivars during different stages of maturation.

\begin{tabular}{|c|c|c|c|c|c|c|}
\hline \multirow[b]{2}{*}{ Genotype } & \multirow[b]{2}{*}{ Maturation stage } & \multicolumn{5}{|c|}{ Flavonoid content } \\
\hline & & Myricetin & Quercetin & Kaempferol & Apigenin & Total \\
\hline & & & & $\mathrm{mg} 100 \mathrm{~g}^{-1} \mathrm{DW}$ & & \\
\hline \multirow[t]{3}{*}{ 09FA-M295 } & I & ND & $0.52 \pm 0.02 b$ & $2.35 \pm 0.15 \mathrm{a}$ & $0.86 \pm 0.04 \mathrm{a}$ & $3.73 \pm 0.20 \mathrm{a}$ \\
\hline & II & $0.14 \pm 0.01 \mathrm{a}$ & $0.56 \pm 0.04 \mathrm{c}$ & $4.29 \pm 0.03 b$ & $1.91 \pm 0.03 \mathrm{c}$ & $6.91 \pm 0.04 \mathrm{c}$ \\
\hline & III & $0.13 \pm 0.00 \mathrm{a}$ & $0.32 \pm 0.01 \mathrm{a}$ & $2.50 \pm 0.05 \mathrm{a}$ & $1.15 \pm 0.02 b$ & $4.13 \pm 0.04 b$ \\
\hline \multirow[t]{3}{*}{ 10FA-M806 } & I & ND & $0.27 \pm 0.02 \mathrm{a}$ & $1.42 \pm 0.07 \mathrm{a}$ & $0.39 \pm 0.01 \mathrm{a}$ & $2.08 \pm 0.10 \mathrm{a}$ \\
\hline & II & $0.16 \pm 0.00 \mathrm{a}$ & $0.46 \pm 0.03 b$ & $3.92 \pm 0.23 b$ & $1.59 \pm 0.04 \mathrm{~b}$ & $6.13 \pm 0.18 b$ \\
\hline & III & $0.17 \pm 0.01 \mathrm{a}$ & $0.82 \pm 0.05 \mathrm{c}$ & $5.72 \pm 0.05 \mathrm{c}$ & $2.39 \pm 0.01 \mathrm{c}$ & $9.10 \pm 0.12 \mathrm{c}$ \\
\hline \multirow[t]{3}{*}{ 10FA-M853 } & I & $0.21 \pm 0.01 \mathrm{c}$ & $0.51 \pm 0.01 \mathrm{a}$ & $3.20 \pm 0.03 \mathrm{a}$ & $1.82 \pm 0.04 \mathrm{~b}$ & $5.74 \pm 0.08 \mathrm{a}$ \\
\hline & II & $0.16 \pm 0.00 \mathrm{~b}$ & $0.53 \pm 0.03 \mathrm{a}$ & $4.21 \pm 0.24 b$ & $1.81 \pm 0.05 \mathrm{~b}$ & $6.72 \pm 0.17 b$ \\
\hline & III & $0.15 \pm 0.00 \mathrm{a}$ & $0.54 \pm 0.05 \mathrm{a}$ & $3.97 \pm 0.16 b$ & $1.31 \pm 0.02 \mathrm{a}$ & $5.97 \pm 0.24 \mathrm{a}$ \\
\hline \multirow[t]{3}{*}{ 12FA-M296 } & I & $0.17 \pm 0.01 b$ & $0.20 \pm 0.02 \mathrm{a}$ & $1.43 \pm 0.09 \mathrm{a}$ & $0.61 \pm 0.03 b$ & $2.40 \pm 0.14 \mathrm{a}$ \\
\hline & II & $0.12 \pm 0.00 \mathrm{a}$ & $0.21 \pm 0.02 \mathrm{a}$ & $2.09 \pm 0.08 \mathrm{~b}$ & $0.41 \pm 0.02 \mathrm{a}$ & $2.83 \pm 0.08 \mathrm{~b}$ \\
\hline & III & $0.17 \pm 0.02 b$ & $0.63 \pm 0.03 b$ & $3.16 \pm 0.12 \mathrm{c}$ & $0.43 \pm 0.03 \mathrm{a}$ & $4.39 \pm 0.19 c$ \\
\hline \multirow[t]{3}{*}{ 12FA-M413 } & I & $0.19 \pm 0.01 \mathrm{a}$ & $0.47 \pm 0.01 \mathrm{a}$ & $3.89 \pm 0.05 \mathrm{a}$ & $1.95 \pm 0.05 \mathrm{a}$ & $6.51 \pm 0.12 \mathrm{a}$ \\
\hline & II & $0.18 \pm 0.01 \mathrm{a}$ & $0.54 \pm 0.01 \mathrm{~b}$ & $5.10 \pm 0.07 \mathrm{c}$ & $2.20 \pm 0.07 \mathrm{~b}$ & $8.02 \pm 0.16 \mathrm{c}$ \\
\hline & III & $0.18 \pm 0.01 \mathrm{a}$ & $0.59 \pm 0.02 \mathrm{c}$ & $4.80 \pm 0.17 b$ & $1.95 \pm 0.19 a$ & $7.52 \pm 0.38 b$ \\
\hline \multirow[t]{3}{*}{ Koyoshi } & I & ND & $0.14 \pm 0.01 \mathrm{a}$ & $1.13 \pm 0.01 \mathrm{~b}$ & $0.61 \pm 0.03 \mathrm{a}$ & $1.88 \pm 0.04 \mathrm{a}$ \\
\hline & II & $0.66 \pm 0.02 b$ & $0.67 \pm 0.03 \mathrm{c}$ & $0.68 \pm 0.02 \mathrm{a}$ & $0.68 \pm 0.03 b$ & $2.68 \pm 0.09 a$ \\
\hline & III & $0.16 \pm 0.01 \mathrm{a}$ & $0.36 \pm 0.02 b$ & $2.88 \pm 0.12 \mathrm{c}$ & $0.90 \pm 0.02 \mathrm{c}$ & $4.30 \pm 0.16 c$ \\
\hline
\end{tabular}

Values are mean \pm SD of three replicates.

Different letters within the column of each genotypes are significant based on Duncan's multiple-range test at $\mathrm{p}<0.05$.

I: Immature, II: intermediate; III: commercial or mature; ND: not detected.

within the range of previous reports by Koh et al. (2009), and higher than those reported by Harnly et al. (2006). In addition, an apigenin that possibly prevents sepsis-induced mortality by decreasing endothelium cell death (Duarte et al.,

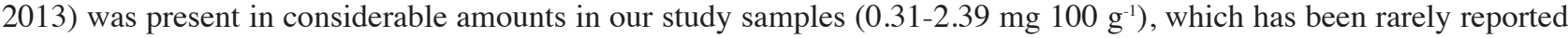
by other authors in previous studies. Our study showed a somewhat different flavonoid profile and lower contents than those observed by Miean and Mohamed (2001), who found myricetin, quercetin, and luteolin at similar ratios in broccoli cultivars from Malaysia. However, in our study, kaempferol and apigenin were found instead of myricetin and luteolin. Such fluctuations in flavonoid profile and content might be due to several factors including genotype, developmental stages, agronomic environment, postharvest conditions, and analytical methods (Vallejo et al., 2003; Koh et al., 2009). The changes in two major flavonoids; quercetin and kaempferol with head ontogeny showed their higher value either in intermediate or commercial stage depending upon the cultivars. These results are inconsistent with previous reports by Krumbein et al. (2007), who found continuous increasing of the flavonoids content during maturation. Similarly, total flavonoid content also showed differential accumulation pattern within the developmental stages with the higher value in either intermediate or commercial stage which was inconsistent to the results by Vallejo et al. (2003). Total

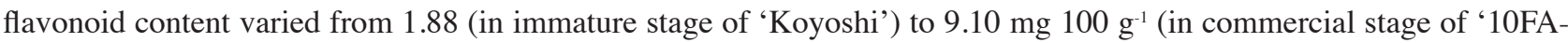
M806'). Flavonoids show strong antioxidant properties and inhibit oxidative stress (Pourcel et al., 2007). We found that all the new-variety candidates had relatively higher total flavonoid content than the commercial cv. Koyoshi during the developmental stages, which therefore suggests a higher nutritional as well as pharmacological value of these cultivars.

\section{Variation in total phenol content}

Phenolic compounds possess various biological properties, most important of which is associated with reducing cancer risk (Manach et al., 2005) in addition to antioxidant properties (Fernandez-Leon et al., 2013). Here we show that total phenol content in broccoli genotypes was greatly affected by both, genotypes and the developmental stages (Figure 1A). Total phenol content increased as the maturity progressed in all the genotypes with the lowest and highest value being in the immature and commercial-stages, respectively. Similar higher total phenolic compound in commercial stage was previously reported by Vallejo et al. (2003), who analyzed different phenolic compounds in the inflorescence of broccoli genotypes during five developmental stages. However, Bhandari and Lee (2016) and Labbe et al. (2016) showed some inconsistent results for total phenolic content in tomato and pomegranates, respectively. The changes in 
Figure 1. Total phenol (A) and ascorbic acid (B) contents in heads of six broccoli cultivars during different maturation stages. I stage: immature; II stage: intermediate; and III stage: commercial stage.

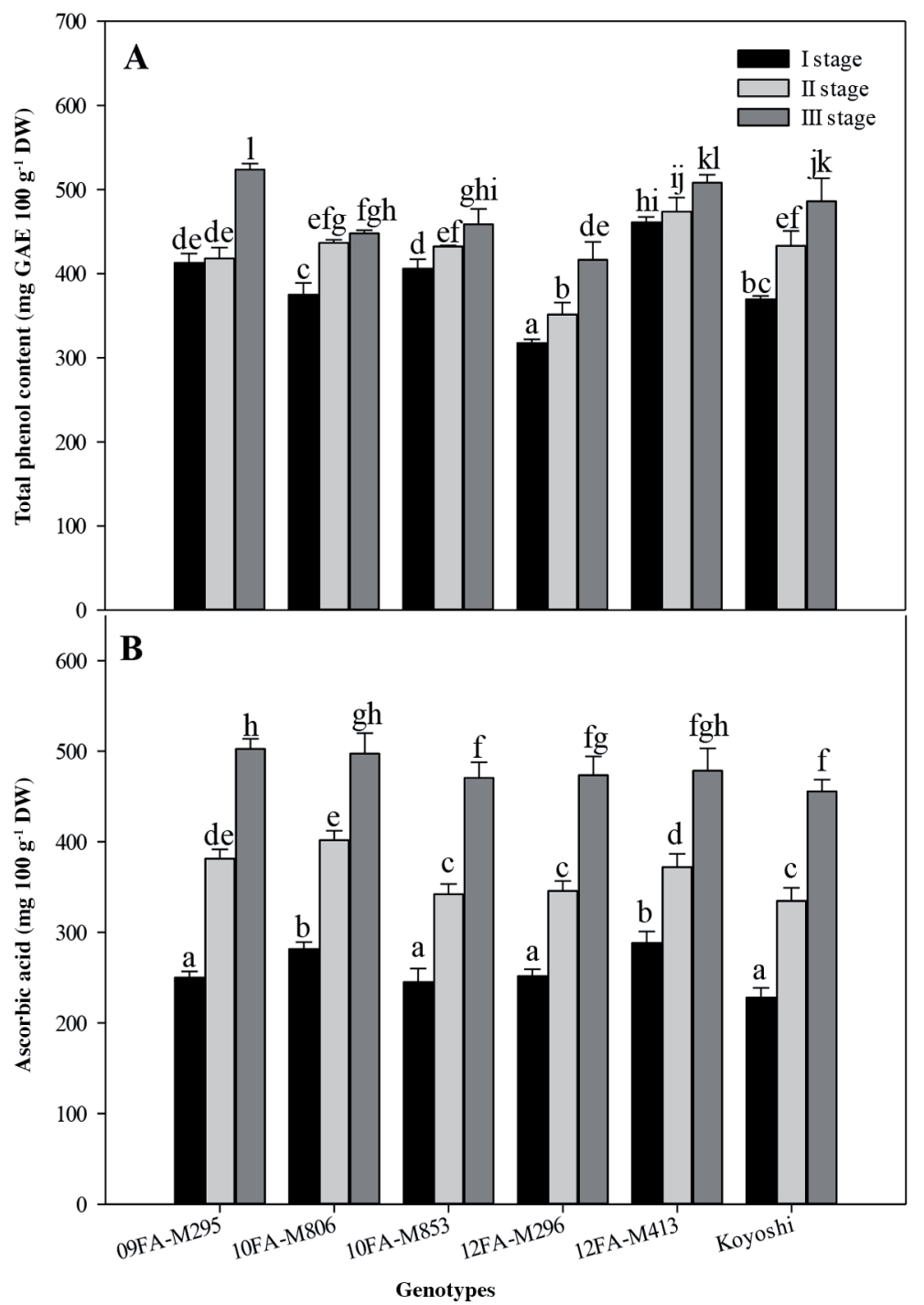

Each bar represents mean \pm SD of three replicates. Different letters in each bar are significant by Duncan's multiple-range test at $\mathrm{p}<0.05$.

GAE: Gallic acid equivalent.

phenolic compounds from the immature to the commercial stage in this study was relatively lower than that observed by Vallejo et al. (2003), which could be due to the difference in genotypes, although several other factors are also known to be responsible for the variation in phenolic compounds in broccoli. Furthermore, the new-variety candidate '09FAM295' showed the highest increment (26.9\%) from the immature to the commercial stage among the six genotypes. In the commercial stage, total phenolic content varied significantly from 416.4 ('12FA-M296') to $523.7 \mathrm{mg} \mathrm{GAE} 100 \mathrm{~g}^{-1}$ ('09FA-M295'). These values are within the range of Bhandari and Kwak (2014) and Jo et al. (2016). Taken together, these results showed that the accumulation of phenolic compounds is dependent not only on genotype but also on the developmental stage of florets. However, quantitative studies on individual phenolic compounds are needed in order to find out the effect of maturity process on targeted phenolic compounds in broccoli. 


\section{Variation in ascorbic acid content}

Ascorbic acid content during the different stages of maturity of broccoli florets is presented in Figure 1B. As in the case of total phenolics, it showed a clear increasing trend from the first developmental stage until the commercial stage in all of the genotypes, thus showing both genotype and maturity stage dependent variation. The differences due to the head developmental stages were relatively higher than the differences due to the genotypes. Ascorbic acid content varied significantly from 228.0 ('Koyoshi') to $288.3 \mathrm{mg} 100 \mathrm{~g}^{-1}$ ('12FA-M413') in the immature stage. Likewise, the significant variation was also observed in the intermediate and the commercial stage among the cultivars with the highest value being

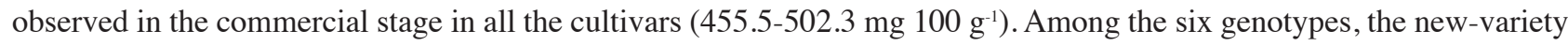
candidate '09FA-M295' showed the highest increment (100.9\%) from the immature to the commercial stage. These results are better than those previously reported by Jo et al. (2016), who analyzed 49 broccoli genotypes. However, the value in this study is within the range found by Koh et al. (2009), who used 80 commercial broccoli types for ascorbic acid analysis. Furthermore, similar to our results, higher ascorbic acid content in matured plant parts was previously reported in vegetables and fruits such as red pepper (Bhandari et al., 2013) tomatoes (Bhandari and Lee, 2016), broccoli (Vallejo et al., 2003), and apricot (Iordanescu et al., 2018). All the new-variety candidates showed relatively higher ascorbic acid content than the control cultivar in their respective developmental stages, suggesting their higher nutritional value.

\section{Variation in antioxidant activities}

Antioxidant capacity, an important parameter for establishing the health benefits of a fruit or vegetable, represents the ability to inhibit the oxidation process. Broccoli exhibits high antioxidant properties, as it possesses diversified natural antioxidants in considerable amounts (Bhandari and Kwak, 2015; Jo et al., 2016). In the present study, three methods were used to evaluate the antioxidant activities: DPPH, ABTS, and FRAP assays as one method alone would have been insufficient for predicting an accurate antioxidant capacity. All the genotypes showed similar trends in each assay with the lowest value being in immature and the highest value in commercial stage of broccoli florets (Figure 2). Similar higher antioxidant activities at matured stage was also observed in fruits such as apricot (Iordanescu et al., 2018). However, antioxidant activities were dependent on the genotype. The free radical scavenging activity determined using DPPH assay varied from $46.2 \%$ to $67.9 \%$. Changes in the radical scavenging activity from the immature to the commercial stage was dependent on the genotype, in which the new-variety candidate '10FA-M806' showed the highest increment (37.0\%) from the immature to the commercial stage. Likewise, the antioxidant activity determined by FRAP assay ranged from 20.1 to $27.9 \mu \mathrm{M} \mathrm{g} \mathrm{g}^{-1}$ in the immature stage to 24.9 to $34.6 \mu \mathrm{M} \mathrm{g}^{-1}$ in commercial stage with the highest increment in '09FA-M295' (62.7\%). The values in this study were within the range of previous reports by Kaur et al. (2007), who analyzed eight commercial broccoli cultivars. ABTS assay also greatly influenced by both the genotypes and developmental stages and ranged from $38.8 \mu \mathrm{M} \mathrm{g}^{-1}$ in the immature stage to $47.1 \mu \mathrm{M} \mathrm{g}^{-1}$ in commercial stage with the $21.6 \%$ increment in '09FAM295'. At the commercial stage, the range of ABTS assay was 38.7 to $47.1 \mu \mathrm{M} \mathrm{g}^{-1}$ on the basis of dry weight which was similar to the previous reports by Penas et al. (2018). However, the value in this study was quite lower than that found in a previous report by $\mathrm{Ku}$ and Juvik (2013). The antioxidant activity measured by each assay was relatively higher in new-variety candidates than in the commercial 'Koyoshi,' with the highest value observed in '09FA-M295'. Such higher antioxidant activities in new-variety candidates can be explained on the basis of their corresponding high ascorbic acid and phenolic contents as determined in this study (Fernandez-Leon et al., 2013).

\section{Correlations between phytonutrients and antioxidant activity}

As the antioxidant contents in broccoli florets were affected by genotypes and head developmental stages, the antioxidant activity which is an indicator of the overall health benefits was also changed. To clarify the contribution of different antioxidants (glucosinolates, ascorbic acid, flavonoids and total phenolics) to the overall antioxidant activity, and interrelationship among the antioxidants, a correlation analysis was performed regardless of genotypes and developmental stages (Table 3$)$. Among the antioxidants, total phenol showed strong positive correlation with ascorbic acid $(0.674 * * *)$ and total flavonoid $\left(0.571^{* *}\right)$, but a non-significant negative correlation with total GSLs content (-0.208). Similarly, major GLSs; GRA, and BRA showed a significant positive and negative correlation respectively with the total phenol content. The results showed strong positive correlations of GRA with all the antioxidant assays, whereas BRA showed a significant negative correlation. However, similar to the Bhandari and Kwak (2015), total GSLs showed a nonsignificant relationship 
Figure 2. Antioxidant activities in heads of six broccoli cultivars during different maturation stages. I stage: immature; II stage: intermediate; and III stage: commercial stage. A: 2,2,-diphenyl-1-picrylhydrazyl (DPPH) assay, B: ferric reducing antioxidant power (FRAP) assay and C: 2,2'-azino-bis(3-ethylbenzothiazoline-6-sulfonic acid) (ABTS) assay.
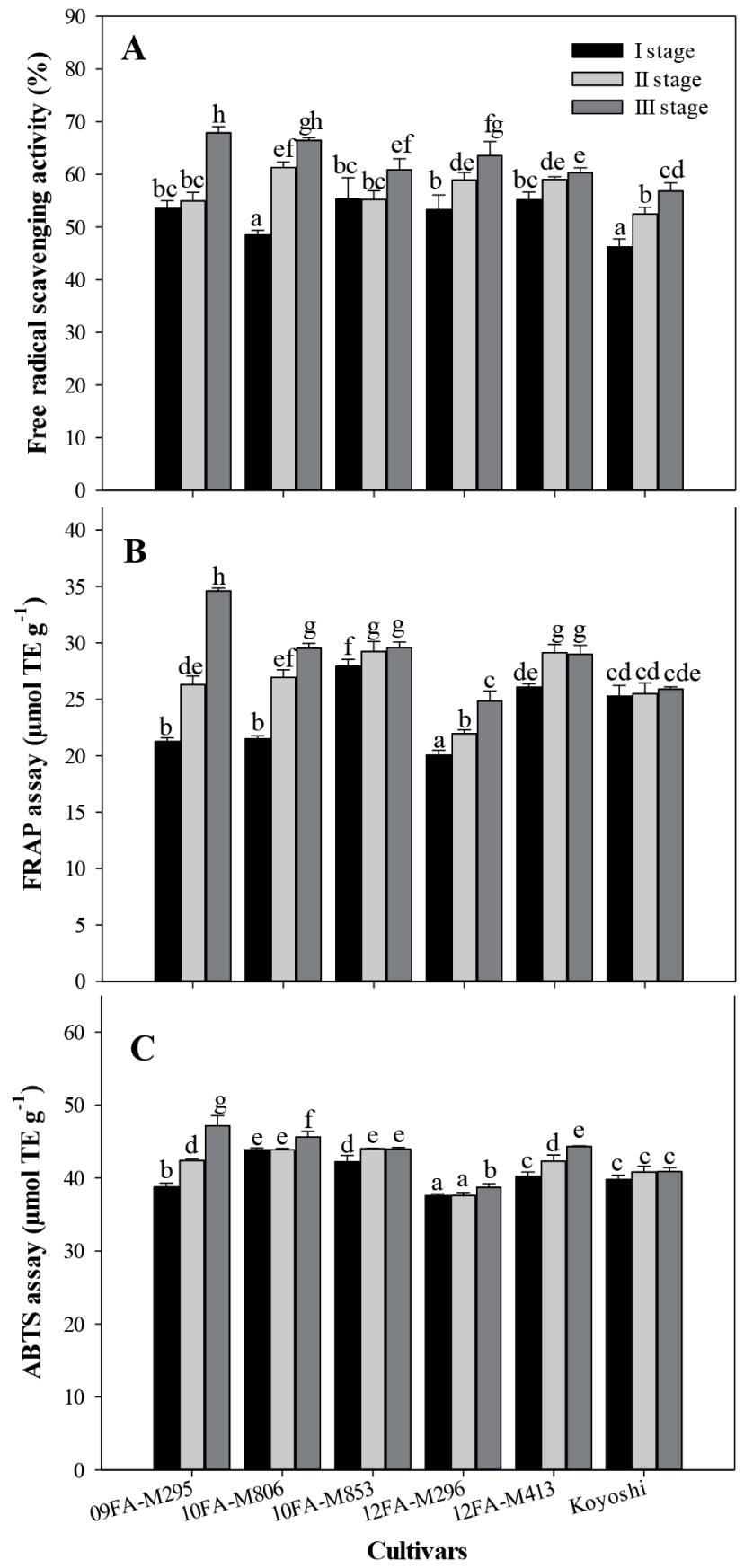

Each bar represents mean \pm SD of three replicates. Different letters in each bar are significant by Duncan's multiple-range test at $\mathrm{p}<0.05$.

TE: Trolox equivalents.

with antioxidant activities which was probably due to the low quantity of GSLs. Likewise, total phenolics and ascorbic acid exhibited the highest positive correlation to the antioxidant activities depending on the antioxidant assay used. These results are consistent with previous reports by Aires et al. (2011) and Bhandari and Kwak (2014). Except for myricetin, all 
the other individual and total flavonoids also showed significant positive correlation with each of the antioxidant assays, which is possibly due to the common biosynthetic pathway of these flavonoids. Furthermore, all individual flavonoids except for myricetin, showed significant positive correlation with each other. The stronger positive correlation between total phenolic and ascorbic acid to the antioxidant assay is in agreement with previous reports by Bhandari et al. (2013) and Aires et al. (2011), possibly due to the higher contribution of those compounds in total antioxidant activity.

Table 3. Correlation between phytonutrients and antioxidant activities in broccoli florets.

\begin{tabular}{|c|c|c|c|c|c|c|c|c|c|c|c|c|}
\hline Attributes & BRA & $\begin{array}{l}\text { Total } \\
\text { GSL }\end{array}$ & Myricetin & Quercetin & Kaempferol & Apigenin & $\begin{array}{c}\text { Total } \\
\text { flavonoid }\end{array}$ & $\begin{array}{c}\text { Total } \\
\text { phenol }\end{array}$ & $\begin{array}{l}\text { Ascorbic } \\
\text { acid }\end{array}$ & FRAP & ABTS & DPPH \\
\hline GRA & $-0.619 * *$ & $0.514^{* *}$ & $-0.503^{* *}$ & $0.306^{*}$ & $0.489 * *$ & $0.332^{*}$ & $0.436^{* * *}$ & $0.432 * *$ & $0.494 * *$ & $0.507^{* *} *$ & $0.383 * *$ & $0.646^{* *}$ \\
\hline BRA & & $0.292 *$ & 0.229 & $-0.460 * *$ & $-0.603 * *$ & $-0.383 * *$ & $-0.567 * *$ & $-0.605 * *$ & $-0.833 * *$ & $-0.615^{* *}$ & $-0.358 * *$ & $-0.774 * *$ \\
\hline Total GSL & & & $-0.364 *$ & -0.222 & -0.201 & -0.216 & -0.243 & -0.208 & -0.221 & -0.138 & -0.099 & 0.023 \\
\hline Myricetin & & & & $0.334^{*}$ & $-0.514^{* *}$ & -0.227 & $-0.334 *$ & 0.014 & -0.208 & -0.093 & -0.104 & $-0.367 *$ \\
\hline Quercetin & & & & & $0.633^{* *}$ & $0.594 * *$ & $0.713^{* *}$ & $0.473 * *$ & $0.464 * *$ & $0.394 * *$ & $0.303^{*}$ & $0.440 * *$ \\
\hline Kaempferol & & & & & & $0.876^{* * *}$ & $0.978 * *$ & $0.538 * *$ & $0.536 * *$ & $0.556^{* * *}$ & $0.473 * *$ & $0.563 * *$ \\
\hline Apigenin & & & & & & & $0.942 * *$ & $0.528 * *$ & $0.276^{*}$ & $0.614^{* * *}$ & $0.526 * *$ & $0.359 * *$ \\
\hline Total flavonoid & & & & & & & & $0.571 * *$ & $0.487 * *$ & $0.602 * *$ & $0.501 * *$ & $0.526^{* *}$ \\
\hline Total phenol & & & & & & & & & $0.674 * *$ & $0.779 * *$ & $0.577 * *$ & $0.552 * *$ \\
\hline Ascorbic acid & & & & & & & & & & $0.616^{* * *}$ & $0.471 * *$ & $0.821 * *$ \\
\hline FRAP & & & & & & & & & & & $0.692 * *$ & $0.592 * *$ \\
\hline ABTS & & & & & & & & & & & & $0.382 * *$ \\
\hline
\end{tabular}

\section{CONCLUSIONS}

We identified changes in glucosinolates (GSLs), total phenolic, flavonoid, and ascorbic acid content as well as antioxidant activities in broccoli florets during the different developmental stages. Two major GSLs, glucoraphanin (GRA) and glucobrassicin (BRA), showed the opposite trend of accumulation pattern during head ontogeny. Total phenolic, ascorbic acid, and GRA content and antioxidant activities increased as maturity progressed. Accumulation of flavonoid was dependent on the genotype with higher content in either the intermediate or the commercial (mature) stage. BRA decreased towards maturity in all the genotypes. Among the six genotypes examined, a new-variety candidate '09FAM295' possessed the highest amount of phytochemicals and showed the highest antioxidant activities, suggesting possible future commercialization of this genotype. Taken together, these results suggest that the health-promoting phytochemicals and antioxidant properties in broccoli show differential accumulation depending upon the nature of the phytochemicals during head ontogeny.

\section{ACKNOWLEDGEMENTS}

This study was supported by the New Scientist Support Project of the Rural Development Administration, Korea (Project No. PJ012300).

\section{REFERENCES}

Aires, A., Fernandes, C., Carvalho, R., Bennett, R.N., Saavedra, M.J., and Rosa, E.A.S. 2011. Seasonal effects on bioactive compounds and antioxidant capacity of six economically important Brassica vegetables. Molecules 16:6816-6832.

Bachiega, P., Salgado, J.M., De Carvalho, J.E., Ruiz, A.L.T.G., Schwarz, K., Tezotto, T., et al. 2016. Antioxidant and antiproliferative activities in different maturation stages of broccoli (Brassica oleracea Italica) biofortified with selenium. Food Chemistry 190:771-776.

Bhandari, S.R., Jung, B.D., Baek, H.Y., and Lee, Y.S. 2013. Ripening-dependent changes in phytonutrients and antioxidant activity of red pepper (Capsicum annuиm L.) fruits cultivated under open-field conditions. HortScience 48(10):1275-1282.

Bhandari, S.R., and Kwak, J.H. 2014. Seasonal variation in phytochemicals and antioxidant activities in different tissues of various Broccoli cultivars. African Journal of Biotechnology 13(4):604-615. 
Bhandari, S.R., and Kwak, J.H. 2015. Chemical composition and antioxidant activity in different tissues of Brassica vegetables. Molecules 20:1228-1243.

Bhandari, S.R., and Lee, J.G. 2016. Ripening-dependent changes in antioxidant, color attributes, and antioxidant activity of seven tomato (Solanum lycopersicum L.) cultivars. Journal of Analytical Methods in Chemistry 2016:ID 5498618.

Bonnesen, C., Eggleston, I.M., and Hayes, J.D. 2001. Dietary indoles and isothiocyanates that are generated from cruciferous vegetables can both stimulate apoptosis and confer protection against DNA damage in human colon cell lines. Cancer Research 61:6120-6130.

Cartea, M.E., Francisco, M., Soengas, P., and Velasco, P. 2011. Phenolic compounds in Brassica vegetables. Molecules $16: 251-280$.

Duarte, S., Arango, D., Parihar, A., Hamel, P., Yasmeen, R., and Doseff, A.I. 2013. Apigenin protects endothelial cells from lipopolysaccharide (LPS)-induced inflammation by decreasing caspase-3 activation and modulating mitochondrial function . International Journal of Molecular Sciences 14:17664-17679.

Fabek, S., Toth, N., Redovnikovic, I.R., Custic, M.H., Benko, B., and Zutic, I. 2012. The effect of nitrogen fertilization on nitrate accumulation, and the content of minerals and glucosinolates in broccoli cultivars. Food Technology and Biotechnology 50(2):183-191.

Faller, A.L.K., and Fialho, E. 2009. The antioxidant capacity and polyphenol content of organic and conventional retail vegetables after domestic cooking. Food Research International 42:210-215.

Fernandez-Leon, M.F., Fernandez-Leon, A.M., Lozano, M., Ayuso, M.C., and Gonzalez-Gomez, D. 2013. Different postharvest strategies to preserve broccoli quality during storage and shelf life: controlled atmosphere and 1-MCP. Food Chemistry 138(1):564-573.

Halkier, B.A., and Gershenzon, J. 2006. Biology and biochemistry of glucosinolates. Annual Review of Plant Biology 57:303-333.

Harnly, J.M., Doherty, R.F., Beecher, G.R., Holden, J.M., Haytowitz, D.B., Bhagwat, S., et al. 2006. Flavonoid content of U.S. fruits, vegetables, and nuts. Journal of Agricultural and Food Chemistry 54:9966-9977.

Iordanescu, O.A., Alexa, E., Lalescu, D., Berbecea, A., Camen, D., Poiana, M.A., et al. 2018. Chemical composition and antioxidant activity of some apricot varieties at different ripening stages. Chilean Journal of Agricultural Research 78:266-275.

Jo, J.S., Bhandari, S.R., Kang, G.H., and Lee, J.G. 2016. Comparative analysis of individual glucosinolates, phytochemicals, and antioxidant activities in broccoli breeding lines. Horticulture Environment and Biotechnology 57(4):392-403.

Jo, J.S., Bhandari, S.R., and Lee, J.G. 2018. Yearly variation in glucosinolate content in inflorescence of broccoli breeding lines. Horticultural Science and Technology 36(3):406-416.

Kaur, C., Kumar, K., Anil, D., and Kapoor, H.C. 2007. Variations in antioxidant activities in broccoli (Brassica oleracea L.) cultivars. Journal of Food Biochemistry 31:621-638.

Koh, E., Wimalasiri, K.M.S., Chassy, A.W., and Mitchell, A.E. 2009. Content of ascorbic acid, quercetin, kaempferol and total phenolics in commercial broccoli. Journal of Food Composition and Analysis 22:637-643.

Krumbein, A., Saeger-Fink, H., and Schonhof, I. 2007. Changes in quercetin and kaempferol concentrations during broccoli head ontogeny in three broccoli cultivars. Journal of Applied Botany and Food Quality 81:136-139.

Ku, K.M., and Juvik, J.A. 2013. Environmental stress and methyl jasmonate-mediated changes in flavonoid concentrations and antioxidant activity in broccoli florets and kale leaf tissues. HortScience 48(8):996-1002.

Labbe, M., Ulloa, P.A., Lopez, F., Saenz, C., Pena, A., and Salazar, F.N. 2016. Characterization of chemical compositions and bioactive compounds in juices from pomegranates ('Wonderful', 'Chaca' and 'Codpa') at different maturity stages. Chilean Journal of Agricultural Research 76:479-486.

Latte, K.P., Appel, K.E., and Lampen, A. 2011. Health benefits and possible risks of broccoli - an overview. Food and Chemical Toxicology 49:3287-3309.

Li, S.H., Fu, J., Watkins, D.N., Srivastava, R.K., and Shankar, S. 2013. Sulforaphane regulates self-renewal of pancreatic cancer stem cells through the modulation of Sonic hedgehog-GLI pathway. Molecular and Cellular Biochemistry 373:217-227.

Manach, C., Mazur, A., and Scalbert, A. 2005. Polyphenols and prevention of cardiovascular diseases. Current Opinion in Lipidology 16(1):77-84.

Miean, K.H., and Mohamed, S. 2001. Flavonoid (myricetin, quercetin, kaempferol, luteolin, and apigenin) content of edible tropical plants. Journal of Agricultural and Food Chemistry 49:3106-3112.

Munyaka, A.W., Oey, I., Loey, A.V., and Hendrickx, M. 2010. Application of thermal inactivation of enzymes during vitamin C analysis to study the influence of acidification, crushing and blanching on vitamin $\mathrm{C}$ stability in broccoli (Brassica oleracea L. var. italica). Food Chemistry 120:591-598.

Pek, Z., Daood, H., Nagyne, M.G., Berki, M., Tothne, M.M., Nemenyi, A., et al. 2012. Yield and phytochemical compounds of broccoli as affected by temperature, irrigation, and foliar sulfur supplementation. HortScience 47(11):1646-1652.

Penas, E., Zielinska, D., Gulewicz, P., Zielinski, H., and Frias, J. 2018. Vitamin C, phenolic compounds and antioxidant capacity of broccoli florets grown under different nitrogen treatments combined with selenium. Polish Journal of Food and Nutrition Sciences 68(2):179-186. 
Perez-Balibrea, S., Moreno, D.A., and Garcia-Viguera, C. 2011. Genotypic effects on the phytochemical quality of seeds and sprouts from commercial broccoli cultivars. Food Chemistry 125(2):348-354.

Podsedek, A. 2007. Natural antioxidants and antioxidant capacity of Brassica vegetables: a review. LWT- Food Science and Technology 40:1-11.

Pourcel, L., Routaboul, J.M., Cheynier, V., Lepiniec, L., and Debeaujon, I. 2007. Flavonoid oxidation in plants: from biochemical properties to physiological functions. Trends in Plant Science 12(1):29-36.

Razis, A.F.A., and Noor, N.M. 2013. Cruciferous vegetables: dietary phytochemicals for cancer prevention. Asian Pacific Journal of Cancer Prevention 14(3):1565-1570.

Thaipong, K., Boonprakob, U., Crosby, K., Cisneros-Zevallos, L., and Byrne, D.H. 2006. Comparison of ABTS, DPPH, FRAP, and ORAC assays for estimating antioxidant activity from guava fruit extracts. Journal of Food Composition and Analysis 19(6-7):669-675

Traka, M., and Mithen, R. 2009. Glucosinolates, isothiocyanates and human health. Phytochemistry Reviews 8:269-282.

Vallejo, F., Garcia-Viguera, C., and Tomas-Barberan, F. 2003. Changes in broccoli (Brassica oleracea L. var. italica) healthpromoting compounds with inflorescence development. Journal of Agricultural and Food Chemistry 51:3776-3782.

Wang, J., Gu, H., Yu, H., Zhao, Z., Sheng, X., and Zhang, X. 2012. Genotypic variation of glucosinolates in broccoli (Brassica oleracea var. italica) florets from China. Food Chemistry 133:735-741. 